\title{
Historical Roots of Physical Therapy Equipment for Cerebral Palsy
}

\author{
${ }^{1}$ Victoria University, Uganda \\ ${ }^{2}$ Guwahati Medical College, India \\ ${ }^{3}$ Department of Medicine, Gajraraja Medical College, India \\ ${ }^{4}$ Department of Respiratory Medicine, Banaras Hindu University, India \\ ${ }^{5}$ Undergraduate Student, MGH Medical College, India
}

Krishna Nand Sharma ${ }^{1 *}$, Kuki Bordoloi ${ }^{2}$, Ankita Kashyap ${ }^{3}$, Mrityunjay Sharma ${ }^{4}$ and Jyoti Sharma ${ }^{5}$

Submission: January 18, 2018; Published: February 08, 2018

*Corresponding author: Krishna Nand Sharma, Victoria University, Victoria Towers, Plot 113, Jinja Road, P.O. Box 30866, Kampala, Uganda, Tel: +256778866339, Email: me@drkrishna.co.in

Abstract

Physical Therapy is an integral part in the management of cerebral palsy children and use of different equipment is very common. This article explores the roots physical therapy and the use of physical therapy equipment in cerebral palsy.

Keywords: History; Physical therapy; Physiotherapy; Cerebral palsy; Inventions

\section{Introduction}

Physical therapy is an integral part of Multidisciplinary (MDT) Approach for paediatric rehabilitation to promote both psychological and functional independence of the cerebral palsy children. It also increases the quality of life of both the child and their family [1-3]. The use of various devices and equipment in physical therapy has been documented [4]. This article explores the roots physical therapy and the use of physical therapy equipment in cerebral palsy.

\section{History of physical therapy}

Though the first physical therapy would have started as manual therapy when the first human would have fallen and then rubbed the injured part to get relief from pain, there are many well documented evidences too.

The legendary physicians like Hippocrates and later Galenus had used physical therapy in forms of massage, hydrotherapy and other manual therapy techniques in 460 B.C. $[5,6]$. The root of term 'physiotherapy' goes back in the 19th century when Per Henrik Ling- the Father of Swedish Gymnastics founded the Royal Central Institute of Gymnastics in 1813 for "sjukgymnast" (sick-gymnast) which included massage, manipulation, and exercise [7]. The first use of the word physiotherapy is found in German Language as the word "Physiotherapie" in 1851 by a military physician Dr. Gleich [8]. 43 years of the German term "Physiotherapie", Dr. Playter [9] coined the word "Physiotherapy". He wrote in the the Montreal Medical Journal -"The application of these natural remedies, the essentials of life, as above named, may be termed natural therapeutics. Or, if I may be permitted to coin from the Greek a new term, for I have never observed it in print, a term more in accordance with medical nomenclature than the word hygienic treatment commonly used, I would suggest the term, Physiotherapy" [9].

\section{History of cerebral palsy}

The story begins in 1830's, when William John Little -a British surgeon started doing research on Cerebral Palsy which used to be an unnamed condition then. In 1861, he referred explained that it was the birth injury due to circumstance during labor in which "the child has been partially suffocated." Since he was the first person to write about this disability, it is referred to as Little's Disease [10]. The term Cerebral Palsy was first used in 1889 when Sir William Osler published his book Cerebral Palsies of Children [11].

\section{Physical therapy in cerebral palsy}

The first Cerebral Palsy Clinic in United States of America (USA) was held 70 years ago on the 25th August, 1947 at the 
St. Louis University Hospital, St. Louis. Apparently looking at the demand and response, a separate Cerebral Palsy Center with Physical Therapy services was established just 3 years later in 1951 [12].

\section{History of physical therapy equipment for cerebral palsy}

After the first apparatus for passive physiotherapy patented in 1924, there has been many inventions in device assisted physiotherapy $[4,13]$. The first muscle stimulator was invented in the year 1938 which was used to treat neuromuscular conditions [4]. But the first high frequency low amplitude current apparatus specially for cerebral palsy children was patented in 1985.This treatment apparatus and methodology used transcutaneous electronic wave to suppress pain and increase motor function [14]. The first patent of Physio-therapy apparatus for mobilization of cerebral palsy children was done in 1968 [15].

Though the first patent of any splint was done in 1851 by Welch [16], Bonnie O'Connell was the first patent a dynamic splint for treating adduction deformities the thumbs of the hands in 1987 [17]. In 1980, Thomas E. Terry and Laurance J. Hoyt, Sr. patented a cerebral palsy arm and hand brace. This device covers the shoulders, upper arm, forearm and hand to control the involuntary spasms and allows controlledgross and fine arm and hand movements in the cerebral palsy patient [18]. In 1991, Tiedeken [19] patented a wheelchair with tremor control device [19]. The first therapeutic exercise apparatus to initiate different postural and equilibrium reactions with to enhancing cerebral palsy children's ability to maintain balance and proper posture was patented in 1989 [20]. The first balancing and walking device for cerebral palsy children was patented in 1957 [21]. The first portable device for hydrotherapy was patented in 1963 by Kinney [22].

\section{References}

1. Günel MK (2011) Physiotherapy for children with cerebral palsy. INTECH Open Access Publisher.

2. Anttila H, Autti Rämö I, Suoranta J, Mäkelä M, Malmivaara A (2008) Effectiveness of physical therapy interventions for children with cerebral palsy: a systematic review. BMC Pediatr 8: 14 .

3. Novak I, Mcintyre S, Morgan C, Campbell L, Dark L, et al. (2013) A systematic review of interventions for children with cerebral palsy: state of the evidence. Dev Med Child Neurol 55(10): 885-910.

4. Sharma KN (2014) Unheard Historical Physiotherapy Inventions, Create Space, USA.

5. Withington ET (1928) Hippocrates/With an English Translation. Harvard University Press, Cambridge, MA: USA.

6. Pettman E (2007) A History of manipulative therapy. J Man Manip Ther 15(3): 165-174.

7. Sharma KN (2012) Exploration of the History of Physiotherapy. Scientific Research Journal of India 1(1): 19-22.

8. Tertouw TJA (2006) The origin of the term Physiotherapy. Physiother Res Int 11(1): 56-57.

9. Playter E (1894) Physiotherapy first: Nature's medicaments before drug remedies; particularly relating to hydrotherapy. Montreal Medical Journal, pp. 811-827.

10. Little WJ (1861) On the influence of abnormal parturition, difficult labours, premature birth, and asphyxia neonatorum, on the mental and physical condition of the child, especially in relation to deformities. Transactions of the Obstetrical Society of London 3: 243-344.

11. Osler W (1889) The cerebral palsies of children, P. Blakiston Son \& Co, Philadelphia, USA.

12. O'Reilly DE, Walentynowicz JE (1981) Etiological factors in cerebral palsy: an historical review. Dev Med Child Neurol 23(5): 633-642.

13. Krueger A (1924) DE Patent No. DE391628C. Deutsches Patent- und Markenamt, Munich, Germany.

14. Liss S, Liss B (1985) US Patent No. US4559948A. U.S. Patent and Trademark Office, Washington, DC, USA.

15. Bernard A (1968) US Patent No. US3362090A. U.S. Patent and Trademark Office, Washington, DC, USA.

16. Welch B (1850) US Patent No. US7626A. U.S. Patent and Trademark Office, Washington, DC, USA.

17. O'Connell B (1987) US Patent No. US4709694A. U.S. Patent and Trademark Office, Washington, DC, USA.

18. Terry TE, Hoyt LJ (1980) US Patent No. US4237873A. U.S. Patent and Trademark Office, Washington, DC, USA.

19. Tiedeken ET (1991) US Patent No. US4996977A. U.S. Patent and Trademark Office, Washington, DC, USA.

20. Bergeron TJ (1989) US Patent No. US4801140A. U.S. Patent and Trademark Office, Washington, DC, USA.

21. Abdallah TC (1957) US Patent No. US2812010A. U.S. Patent and Trademark Office, Washington, DC, USA.

22. Kinney CM (1963) US Patent No. US3092101A. U.S. Patent and Trademark Office, Washington, DC, USA.

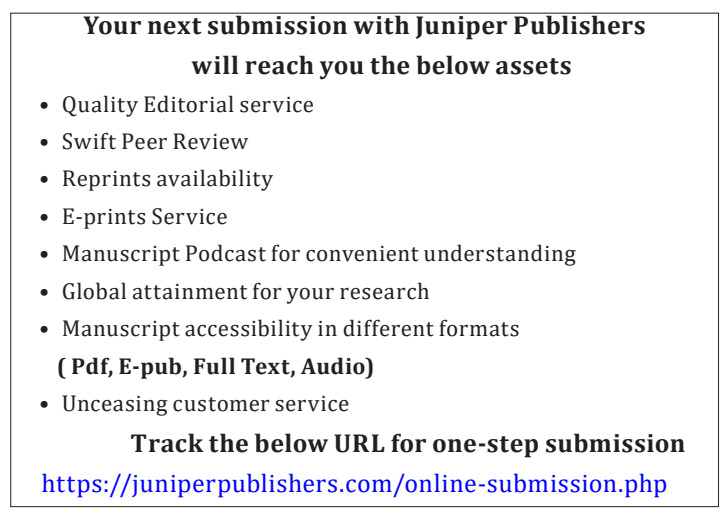

